\title{
The Impact of Project-Based Learning on Achievement and Student Views: The Case of AutoCAD Programming Course
}

\author{
Halil Coşkun Çelik ${ }^{1}$, Haydar Ertaş ${ }^{2} \&$ Aziz İlhan ${ }^{3}$ \\ ${ }^{1}$ Mathematics and Science Education Department, Faculty of Education, Siirt University, Turkey \\ ${ }^{2}$ Building Supervision Department, Çemişgezek Vocational School, Munzur University, Turkey \\ ${ }^{3}$ Accounting and Tax Department, Çemişgezek Vocational School, Munzur University, Turkey \\ Correspondence: Assist. Prof. Dr. Halil Coşkun Çelik, Mathematics and Science Education Department, Faculty \\ of Education, Siirt University, Turkey.
}

\author{
Received: February 15, 2018 Accepted: March 20, 2018 Online Published: September 6, 2018 \\ doi:10.5539/jel.v7n6p67 URL: https://doi.org/10.5539/jel.v7n6p67
}

A section of the present paper was presented as an abstract proceeding at International ISSEC 2017 Symposium.

\begin{abstract}
The aim of the study was to determine the impact of project-based learning on academic achievements of vocational school of higher education students and to investigate their views on the topic. In the study, a mixed descriptive design where qualitative and quantitative data were both collected and analyzed. The quantitative part was conducted with relational screening method and the qualitative part was conducted with descriptive analysis method. The study group included 13 freshmen students attending the vocational school of higher education, building inspection program in a university located in Eastern Anatolia region in Turkey during the 2016-2017 academic year spring semester and selected with convenience sampling method. The study was conducted during the 14 weeks long period where the related programming course was instructed. In the study, quantitative data were collected with an achievement test that measured the academic achievements of the students in AutoCAD programming course. The qualitative data were collected with a structured interview form designed to collect the student views on the related course. Quantitative data were analyzed with the t-test and the descriptive analysis method was used to analyze the qualitative data. In conclusion, it was determined that project-based learning had a positive impact on academic achievement. Furthermore, students expressed that they achieved meaningful learning as a result of the project-based learning application and the method was adequate for the instruction process, improved their interest in the course and related the content with daily life.
\end{abstract}

Keywords: academic success, project-based learning, autoCAD instruction, vocational school students

\section{Introduction}

In the instruction process, it is known that Turkish education system has been transformed from a teacher-centered learning approach into a student-centered approach during recent years. In fact, this led to the prominence of student-centered approaches. One of the most important student-centered approaches is the Project-Based Learning Approach. In this approach, students actively participate directly in the instruction process, interacting directly with learning areas. Students easily forget the information they learn only by hearing. However, an educational activity that they directly participate in leads to better comprehension of the topic and the retention of the learned knowledge (Başar, 1992). Project-based learning should enable students to acquire new knowledge by asking questions, researching, solving problems, making decisions, conducting cognitive or psychomotor skills-based designs. The products that students construct only by using previous knowledge could not be called projects, but only exercises (Kalayc1, 2008).

Project-based learning is defined by Erdem and Akkoyunlu (2002) as "a learning approach based on project development, imagination, planning and construction. It emphasizes a process where learners plan their own learning processes individually or in a group to reach certain goals, developing their skills of collaboration, responsibility, collecting information, and organization of collected information." Project-based learning is an education and instruction model that includes problem-solving and other meaningful learning of the students, 
allowing the students to work alone to organize their knowledge and finalize their work, create their own products and focused on concepts and scientific principles (Cole, Means, Simkins \& Tavali, 2002).

Anonymous (2003) described the six stages of the project-based learning process as follows: question/problem, planning, programming, guidance, assessment and evaluation. Learning in project-based learning means continuous reorganization of the intellectual structure of the learner based on the design-based and process-oriented structure of the approach. Thus, project-based learning requires process-oriented and in-classroom interactive environments. These learning environments are technology-based environments where students construct and guide their own learning, thereby developing their creativity, they attempt to solve the problems they encounter in collaboration, they make decisions on their own achievements, the life is transported into the classroom, and families actively participate in the learning process (Erdem, 2002).

Projects are defined as individual or collaborative work conducted by students for a long time on a task to achieve a concrete product alone or in small groups. The main objective of project work is to assist the students to develop responsibility of self-learning and to motivate them to work in collaboration with others (Saban, 2002). The object of project studies is to train individuals who can collaborate, solve problems and produce different solutions, transform this process into lifelong learning and produce a product and conduct research for this purpose, question, collect information and could use the collected information in an accurate and systematic manner (Çiftçi \& Sünbül, 2005).

In project-based learning, learners decide how to approach a problem and which activities they should carry on. They collect information from a wide variety of resources and obtain information via analysis and synthesis. Students comprehend the topics better since they enjoy the project work better and they have the opportunity to learn by living (Winn, 1997). Project-based learning develops the high level cognitive skills such as data analysis, problem solving, decision making, etc. and improves their sense of responsibility for the physical and social environment (Dori \& Tal, 2000).

The primary goal of the project-based learning should be to enable the student to discover self-learning profile and style, and thus to teach how to learn (Vaiz, 2003). Implementation of project-based learning in higher education and presentation of the results with a paper is important for providing an example for other academicians who consider implementing this learning approach in their courses (Kalayc1, 2008). Project based learning is an approach that can be used at every stage in higher education, in suitable departments or courses. This approach is used in certain faculties and vocational higher education institutions properly based on its rules and principles, however this is not prevalent. For example, certain departments in Gazi and Ankara Universities, Faculties of Medicine, and in Dokuz Eylül University, Faculty of Engineering have adopted project-based learning (Kalayc1, 2008).

Certain studies in the literature compared the effects of project-based learning approach and traditional instruction method on academic achievements of students in different classes and courses. The results of these studies demonstrated that project-based learning has positive effects on academic achievements of students when compared to traditional teaching. Atıcı and Polat (2010) studied the impact of project-based learning on students' academic achievements and their views in web design course. The study results demonstrated that project-based learning has increased student achievement compared to traditional instruction. In a study by Özyurt and Özyurt (2017), the student views on project-based learning implemented in visual programming course were examined. As a result, it was demonstrated that project-based learning provided significant contributions to the learning process. In a study by Gömleksiz and Fidan (2013), the views of university students on the effects of project-based learning in web design course were obtained. Based on the study findings, it was determined that project-based learning led to effective learning, active participation and retention of knowledge. Furthermore, it was concluded that project-based learning provides practice opportunities, increases motivation through collaboration, and thus, it should be used in similar courses. In addition, Nielsen Nielsen, Du, and Kolmo (2010) found that project-based learning improved the achievements of engineering students. However, there are also studies that claimed that project-based learning did not have a superior effect on student achievements although it had positive effects on achievement (Avci, 2006; Özyurt \& Özyurt, 2017; Yıldız \& Özdemir, 2012). In certain studies, the effects of the activities designed with Geogebra mathematics software on student achievement were examined and compared to traditional instruction approach. Thus, Öztürk (2012) determined that Geogebra mathematics software had a positive impact on student achievement in 8th grade mathematics course trigonometry and slope topics and Van Hiele geometry level. Özçakır and Çakıroğlu (2017) suggested that Geogebra provided positive support to junior high school 7th grade students in the instruction of achievements in mathematics course areas of quadrangles topic. 
One of the computer software used in applied technical fields is the AutoCAD software. AutoCAD, known also as an instructional process, requires student proficiency rather than being difficult. It actually improves individual's affective skills such as creative thinking, problem solving and critical skills. Technology does not only improve motivation, but it also helps students recognize the significance of learning. The use of technologies such as AutoCAD allows students to directly participate in learning and learning processes (Holzinger, 1997; Sidek \& Mohd Ariffin, 2011; Sharples, 2000; Sharples, Corlett, \& Westmancott, 2002). It is important to use this software to provide independent computer-aided drawing information in computer aided design and technical drawing courses. Because, today, the communications between building inspection offices, architectural and engineering bureaus, design bureaus, administration and offices and building sites are conducted on electronic media. Today, AutoCAD software is accepted as an international standard in computer-aided drawing. This software is also used as a useful tool for data entry in general purpose engineering software. Therefore, it is necessary to provide basic AutoCAD knowledge in the core curriculum courses (AutoCAD, 2017). Computer Aided Instruction could be applied in courses in engineering and technical education such as Computer Aided Design and Computer Aided Manufacturing. Although AutoCAD is a developed for design and manufacturing, it also has an educational function via AutoLISP and DCL. Based on the abovementioned information, the significance of AutoCAD skills for building inspection department students in vocational schools of higher education, the capability of students to create project outputs using this software and the suitability of the course content and project-based learning with respect to the instructional methods utilized in this course demonstrate the importance of the present study for the literature. It is also considered that cognitive and emotional views of the students on this course and instructional method are important.

\subsection{The Aim of the Study}

The objective of the study was to determine the impact of project-based learning applications on the academic achievements of vocational school for higher education students in AutoCAD programming course and to examine their views on the topic. It was stipulated to investigate the sub-objectives presented below based on the abovementioned general objective.

1) What was the AutoCAD achievement score level of the students before and after project-based learning applications?

2) Was there a significant change in students' AutoCAD programming course academic achievements as a result of project-based learning applications?

3) What were the views of students on AutoCAD education based on project-based learning applications?

\section{Method}

\subsection{Research Design}

The study was conducted with a mixed design that included quantitative and qualitative research methods. In the quantitative section, the effect of the independent variable (project-based learning) on the dependent variable (students' achievements in the AutoCAD course) was investigated with single group pretest-posttest weak experimental design. In this design, the independent variable is applied to a group and measurements are conducted before and after the application. When there is significant difference between the mean pre-test and post-test scores obtained by the group in the measurement instrument, it is concluded that the application was effective (Karasar, 2008). In the qualitative section, the impact of project-based learning applications on the academic achievement of students in AutoCAD programming course was determined. For this purpose, the written views of all students were obtained and a descriptive analysis was conducted on the collected data.

\subsection{The Study Group}

The study group included 13 undergraduate freshmen students attending the vocational school of higher education, building inspection program in a university located in Eastern Anatolian region in Turkey during 2016-2017 academic year spring semester. These students were randomly selected among freshmen building inspection department students who were attending the AutoCAD course and with homogenous achievement levels. Thus, convenience sampling method was preferred as the implemented sampling method in the study. The convenience sampling method is selection of the sample from easily accessible and applicable subjects due to time, money and labor force limitations. Initially, the university where the sampling would be selected was determined, and then the students who were attending the related program in this university were selected with convenience sampling method (Büyüköztürk, 2016, p. 92). 


\subsection{Data Collection Tools}

Achievement Test (AT) and Structured Interview Form (SIF) were used as data collection tools in the study. AT: This is a multiple-choice test that included 20 questions and developed by the authors to measure the academic achievements of the students in AutoCAD programming course (See Appendix 1). The test questions were developed by the authors after the required literature review was conducted based on the course learning outcomes. During the design of the test, the learning outcomes were examined and the content validity of the test was ensured by obtaining the expert views of 2 faculty members in the field of building inspection and 1 faculty member in the field of educational sciences. The correct answers received 1 point and incorrect questions received 0 point in the test. Thus, the highest possible score in the test is 20 and the lowest possible score is 0 points. The reliability of the test is calculated with Kuder Richardson-20 (KR 20). The reliability coefficient is 0.761. SIF: Developed by the authors, this form aimed to obtain the student views on the AutoCAD programming course. The form included 10 open-ended questions developed by the authors after conducting a literature review. The form questions were on what the students liked the most during the instruction of the course, their positive/negative views on the course, the significant challenges they faced during the instruction, and their views on how AutoCAD can be used in other disciplines. For the form validity, the same experts who reviewed the AutoCAD Achievement Test were consulted. Based on the feedback, two questions were considered inadequate based on technique and content and were removed from the form. Thus, the structured interview form that included 8 questions was finalized. The form was applied to all students. Some of the questions on the form are as follows: What do you think is/are the benefit/benefits of the instruction of this course with project-based learning approach for your achievements? Which aspect of instruction with project-based learning approach you liked the most? Why? What did you feel about project-based learning approach during the instruction of the course? What kind of skills you achieved when the course was instructed with project-based learning approach? The student responses were transferred to tables using MS Excel software and the general trends in the student views were determined with descriptive analysis.

\subsection{Application Process}

In the study, project-based learning instructions were carried out by the second author. In order to determine the impact of the project-based learning on the academic achievement, the achievement test was applied to the students as the pre-test and post-test in the quantitative part in the study. In the qualitative part, the structured interview form was applied as a posttest to obtain the student views on the subject. The information about the implementation of the instruction method in the present study is presented in Table 1.

Table 1. Project-based learning application process

\begin{tabular}{llll}
\hline Group & Before the application & Application & After the application \\
\hline \multirow{2}{*}{ Student } & Pretest & $\begin{array}{l}\text { Project-based learning } \\
(14 \text { weeks })\end{array}$ & $\begin{array}{l}\text { Posttest } \\
(\text { AT }+ \text { SIF })\end{array}$ \\
\hline
\end{tabular}

During the application stage of the study, the course topics were spread over fourteen weeks (42 periods) based on the AutoCAD course hours to comply with the course curriculum and to achieve the learning outcomes. AutoCAD course instruction was conducted in the computer lab based on the course syllabus and questions on the topic were asked to the students at the end of each class. In certain parts of the instruction process, methods such as discussions, question and answer sessions were conducted, and applications were instructed and discussed by the second author. Activities were carried out in a classroom environment where students were actively involved by the second author using the project-based learning approach. In order to measure the effectiveness of the learning process, project evaluation form, self-evaluation form, worksheets, student product file evaluation form and the interview form were used. In the instruction process, the students were initially asked how the project outputs could be drawn in the AutoCAD software. Based on the answers, the course project outputs are presented in the computer environment and solutions were demonstrated. Thus, it was attempted to determine the efficiency of the method on the academic achievements of the students. The learning outcomes of the AutoCAD-assisted project process are presented in detail at the end of the present paper (Appendix 2).

\subsection{Data Analysis}

Qualitative and quantitative data were obtained as a result of the applications conducted in the study. In cases where the number of data in each group was less than 30, nonparametric tests were utilized (Büyüköztürk, 2016). 
Thus, nonparametric Mann-Whitney U-Test and Wilcoxon signed-rank test methods were used in the SPSS 21.00 software for the analysis of quantitative data. The qualitative data were analyzed by descriptive analysis using the MS Excel software.

\section{Findings}

\subsection{Quantitative Findings on Academic Achievements of the Students}

The descriptive statistics were conducted on the data obtained from the achievement tests in the quantitative section of the study. These statistics were interpreted based on the pretest/posttest scores of the students. The mean scores obtained in the achievement test based on the student responses were examined using standard deviation and levels. Related findings are presented in Table 2.

Table 2. Comparison of students' academic achievement pretest and posttest scores

\begin{tabular}{llcccccc}
\hline Application & $\mathrm{N}$ & Number of Items & $\overline{\mathrm{X}}$ & S.S & Sd. & t. & p. \\
\hline Pretest & 19 & 20 & 6.316 & 2.191 & \multirow{2}{*}{36} & \multirow{2}{*}{8.234} & \multirow{2}{*}{.000} \\
Posttest & 19 & 20 & 11.632 & 1.765 & & & \\
\hline
\end{tabular}

Table 2 demonstrates that the students' mean pre-test score was $\bar{X}=6.316$, while the mean posttest score was $\bar{X}=11.6322$. Thus, it was determined that the mean achievement levels of the students improved after the conducted project-based learning applications $\left(\bar{X}_{\text {posttest }}=11.632>\overline{\mathrm{X}}_{\text {pretest }}=6.316\right)$. Dependent samples t-test results showed that the difference between the students' pre and post test scores was statistically significant $\left(\mathrm{t}_{36}=8.234\right.$ : $\mathrm{p}=.000<.05)$.

\subsection{Qualitative Findings on Student Views}

In the study, AutoCAD activities related to AutoCAD programming course learning achievements were designed and 8 open-ended questions were asked after the course to evaluate the views of the students in the study group. The data obtained with the structured interview form are presented with direct quotes. In the process of quoting student views, initially the student views expressed for each question were examined, and the most frequent responses were directly quoted. Furthermore, general trends among all responses were discussed in a descriptive manner. In the presentation of the quotes, student names are coded such as $\mathrm{K} 1, \mathrm{~K} 2, \mathrm{~K} 3, \ldots$ in compliance with the scientific ethics rules.

The first question that was posed to the students was, "What do you think is/are the benefit/benefits of the instruction of this course with project-based learning approach for your achievements?" It was observed that most students replied to the question as "they achieved psychomotor skills as a result of the projects they conducted with AutoCAD applications" $(\mathrm{N}=6)$ and "it contributed to better comprehension of the topic" $(\mathrm{N}=5)$. The views of certain participants were as follows:

K5: "It enabled us to be more informed and practical in project drawings." future."

K6: "We learn drawing and reading the project in computers. This course will be beneficial for us in the

K8: "I think that it is beneficial for comprehending and learning faster and learning the meanings of the symbols used in the software faster."

In addition to the abovementioned responses, the following response by a student (K10) could be considered as an interesting finding on the significance of AutoCAD software: "I think I can draw the project, learned how to read the project and I designed creative projects with a higher awareness with the project-based learning approach."

In order to measure the emotions that students experienced during the instruction of the course, the following question was posed: "Which aspect of instruction with project-based learning approach you liked the most? Why?" Students often indicated that "the course process became more fun" $(\mathrm{N}=5)$ and "the course was no more boring" ( $\mathrm{N}=5)$ as a result of project-based learning application. The views of certain participants were as follows:

K5: "I quite liked the fact that the professor visually provided information using videos as we draw."

K7: "Observing it visually enabled us to comprehend the course better and the course was quite entertaining." 
K11: "I liked the project drawing method. Because, working with this method makes the course more fun."

In addition to the answers mentioned above, another student (K13) stated that "I liked the instruction of the course in a purely applied manner. I liked the fact that the project-based learning was not a rote-based method," demonstrating the fact that the use of project-based learning in the educational process is a significant factor in the retention of the learning in instructional activities.

In order to obtain the views of the students on project-based learning used in the course process in the study, the following question was utilized: "Was the method used in the instruction of this course important, please explain the reasons?" Most students stated that "project-based learning was important" and "it changed the perspectives of the students on the course and expanded their horizon" $(\mathrm{N}=9)$. The views of certain participants were as follows:

K4: "It is important, because it made me comprehend the course content better."

K5: "It is important. Because, the method made us participate in the course better, reinforcing our knowledge."

K9: "It is important, because it improves one's interest in the course."

Furthermore, in addition to the answers mentioned above, another student (K12) stated that "It is important because we actively participated in the class and developed our method creativity skills," and this could be considered as a finding that evidenced the significance of the project-based learning in the development of creativity skills and active participation of the individual in classroom activities.

In order to measure the negative aspects of the project-based learning, students were asked the following question: "What was the most challenging aspect for you during the instruction of the course and why? Students often stated that they mostly experienced problems in "computer applications" $(\mathrm{N}=8)$. The views of certain participants were as follows:

K4: "There were a high number of models that needed to be constructed in the software, which made it difficult for me to organize my projects on the computer."

K10: "I experienced difficulties in the applications I conducted on the computer in the project drawing process and when I was transferring the data to the isometric paper."

K11: "Computer applications for certain projects were difficult and complex."

In addition to the answers mentioned above, the response of another student (K3) that "I experienced difficulties during the drawing process in the project due to time constraints" could emphasize the point that the utilized method may lead to time management problems.

In the study, to measure students' emotions about the learning process, the following question was posed "What did you feel about project-based learning approach during the instruction of the course?" The students mostly expressed that they felt "excitement" $(\mathrm{N}=10)$ about the process. The views of certain participants were as follows:

K5: "I was excited, I became aware that I can think at a high-level."

K6: "I was excited about feeling that I can succeed."

K9: "I was excited because at one moment I felt like I was working at an actual professional environment."

Also, in addition to the responses given above, the student coded K4 stated that "it varies based on the project. When it is confusing, I feel bad," which could demonstrate that the level of the projects was important for the adopted method.

To measure the skills that the students achieved and were aware of this achievement, the following question was posed: "What kind of skills you achieved when the course was instructed with project-based learning approach?" The students mostly stated that they achieved "Project reading" $(\mathrm{N}=7)$ skills. The views of certain participants were as follows:

K1: "My project reading and accordingly, high-level thinking skills developed thanks to the project-based learning."

K5: "My skills of making comments about the project and project reading developed."

K6: "I noticed that my project design and interpretations skills in the AutoCAD software developed." 
Furthermore, in addition to the answers mentioned above, a student (K3) stated that "the fact that we could work on the projects in detail led to the achievement of three-dimensional spatial thinking skills," which suggested that project-based learning was important for the development of individual's spatial intelligence.

In order to measure the students' level of establishing correlations between the subject areas, the following question was posed: "In which courses you would like to use project-based learning in the department?" The students mostly stated that the method can be applied in "Field Information Courses" $(\mathrm{N}=11)$. The views of certain participants were as follows: as well."

K5: "Due to our profession, I would like the project-based learning to be utilized in other field courses

K6: "It can be adequate to use the project-based learning in the structural analysis course."

K7: "I think the concrete and damage courses are adequate for project-based learning."

Finally, in order to measure how helpful the method was in making the students relate with the daily life, the following question was included in the interview: "Do you think that the project-based learning utilized in the instruction of this course relates the course content to daily life?" The students mostly mentioned that "project-based learning is effective in relating the course content to daily life" $(\mathrm{N}=10)$. The views of certain participants were as follows:

K9: "Yes, because we will be drawing projects all the time when we will practice the profession."

K10: "Yes, it is related, because I think that my self-esteem in daily life would improve thanks to project-based learning."

K14: "Yes, in my opinion, even the most primitive individuals use projects when building their shelters."

It is possible to suggest that the project-based learning positively affected the instruction process based on the student views. Via project-based learning, students were able to restructure their knowledge and displayed behavior in accordance with the objectives of the program. Student statements demonstrated that thanks to project based learning, their project reading skills, their skills to comment on projects, and their skills to be aware of the significance of the projects in daily life improved.

\section{Discussion, Conclusion and Recommendations}

As a result of the present study that aimed to determine the impact of project-based learning applications on the academic achievements of vocational school of higher education students in AutoCAD programming course and to investigate the student views on the topic, it was concluded that the conducted applications had a positive impact on academic achievements of the students. In the literature, there are project studies that supported the abovementioned result (Atici \& Polat, 2010; Gömleksiz \& Fidan, 2013; Khaliq, Alam \& Mushtaq, 2015; Nielsen, Du \& Kolmos, 2010; Özyurt \& Özyurt, 2017), while there are others, albeit limited in number, that suggested the opposite (Avci, 2006; Özyurt \& Özyurt, 2017; Y1ldı \& Özdemir, 2012).

After the quantitative part of the study was completed, the qualitative part was conducted, and SIF was applied to evaluate the student views in depth. The data obtained in the interviews were analyzed with descriptive analysis and the results were presented as direct quotes. Students were asked about the benefits of instructing the course with project-based learning approach, and they mostly stated that the projects conducted with AutoCAD application improved their psychomotor skills and contributed to better comprehension of the topic. In other words, students stated that their academic knowledge and skills were positively affected by project based learning. Atıc1 and Polat (2010) concluded that the development of academic knowledge and skills of the students in a course was positively affected by project-based learning. Demirel (2007) also stated that when conducting projects, project-based learning allowed the students to study with their own methods and establish their own knowledge structures. Thomas (2000) also stated that the use of project-based learning in the classroom contributed significantly to the acquisition of knowledge by students.

In order to determine the emotions experienced by the students during the instruction of the course, they were asked which aspect of the project-based learning instruction process they liked the most, and it was determined that the course became more fun and was no longer boring when the course was instructed with the project-based learning approach. In other words, the students were more interested and actively participated in the instruction process. In a study by Curtis (2002), it was stated that teachers and parents were satisfied with the connected and orderly commitment of the students in the project. Furthermore, Zoller (1991) stated that active participation of the students in the process enabled them to shape their ideas and demonstrate their perspectives. Moreover, in 
their study, Saraçoğlu, Akamca and Yeşildere (2006) stated that students have the opportunity to conduct activities based on their special needs and interests thanks to the project-based learning.

To determine the student views on the method used in the course process, they were asked about the significance of the approach used during the course. It was determined that the project-based learning approach was important and changed their views about the course. It could be suggested that the students considered that the approach changed their views on the course because they considered the related learning approach as important and that they achieved certain top-level skills due to this approach. In a study by Sert Çıbık (2009), it was reported that the project method was beneficial for students who do not like to participate in the instruction, and it developed the problem solving, synthesis and critical thinking skills of the students.

In order to determine the negative aspects of the project-based learning approach, the students were asked to indicate where they experienced problems during the instruction of the course and they stated that they experienced the most difficulty in computer applications. However, certain students also stated that these skills improved when the teaching process was over. Based on this finding, it can be suggested that the project-based learning positively affected students' achievements. In a study by Korkmaz and Kaptan (2001), it was stated that students acquire certain skills through project-based learning, and one of these skills was technological literacy skill.

In the study, students were asked what they felt when they saw the expression of algebraic structures with geometrical shapes to measure the emotions of students about the instruction process and it was determined that the feeling of excitement was prevalent among the students. Based on this finding, it is possible to suggest that project based learning improved the students' attitudes towards the course. In a study by Demirel (1993), it was reported that project-based learning is an important method in improving students' attitudes towards the course and their self-assessment. Furthermore, Kalaycı (2008) stated that the students were very excited for constructing a creative product.

In order to measure the skills that the students developed with self-awareness, the skills that they thought they acquired due to the instruction of the course with project-based learning approach, and it was determined that the students acquired project reading skills. This may be due to the fact that project-based learning positively affects project development skills. Erdem (2002) reported that project-based learning is a teaching approach where the concept of learning based on project development is predominant. The findings of this study were consistent with the present study findings.

In order to measure the level of the students in establishing correlations between the subject areas, they were asked to identify the courses that project-based learning approach would be adequate in their view and the students indicated that the approach could be used in field information courses. This may be due to the fact that the students perceived the project-based learning approach as an interdisciplinary approach. In a study by Vaiz (2003), it was stated that the project-based learning is a classroom activity model that adopts long-term, interdisciplinary learning activities that integrate student-centered and real-world topics and applications instead of short, isolated, teacher-centered classroom applications. This result is consistent with the present study findings.

Finally, the students were asked whether the project-based learning approached used to instruct the course could relate the course content with daily life to measure the assistance provided by the method they utilized to relate with the daily life and it was determined that the project-based learning approach was an effective method for establishing a relation with the daily life. This can be due to the fact that students could solve the daily life problems while they were actively involved in the process, and they were able to produce a concrete product. There are studies in the literature that support this finding. In a study they conducted, Korkmaz and Kaptan (2001) reported that project-based learning integrated the products that the students created and their performances in real life.

In conclusion, based on quantitative findings of the study, it can be suggested that the project-based learning approach increases achievements in the instruction process and leads to a significant difference when compared to traditional teaching methods. Furthermore, students generally stated that the project-based learning affected the instructional process positively when expressing their views. Via project-based learning, students were able to exhibit behavior in line with the objectives of the restructured program. Student statements demonstrated that they developed project reading skills, the skill of interpreting the projects, and awareness on the significance of the projects in daily life through the project-based learning. Based on the current study findings, the following can be recommended for future studies: further studies on the use of project-based learning in computer-aided learning environments in other branches can be conducted. Project-based learning approach can be used in 
computer-aided learning environments and new studies can be conducted at different educational levels (primary school, junior high school, high school, colleges, etc.). On the other hand, only the achievement test was applied to the 13 participating students as the data collection instrument in the quantitative part of the study, and the obtained data were analyzed with a weak experimental design. Thus, different sampling approaches and different data collection instruments could be recommended for future studies on project-based learning applications and to conduct the studies with an experimental design where at least study and control groups are present.

\section{References}

Anonymous. (2003). Learning in action. The George Lucas Educational Foundation.

AutoCAD. (2017). Retrieved from usa.autodesk.com/

Atıc1, B., \& Polat, H. (2010). The effect of project-based learning approach on students' academic achievements and views in web design instruction. Turkish Journal of Computer and Mathematics Education, 1(2), 122-132.

Avc1, A. (2006). The effect of integrated programming software assisted project-based learning on students' electronic circuit design and development performances and retention in electronic education set design. (Unpublished master's thesis), Çukurova University, Institute of Social Sciences, Adana.

Başar, V. (1992). Applied (project) physics instruction-assignments exhibitions and competitions for junior high schools. İstanbul: National Education Publishing.

Büyüköztürk, Ş. (2016). Data analysis handbook for social sciences (22th ed.). Ankara: Pegem Akademi Publishing.

Cole, K., Means, B., Simkins, M., \& Tavali, F. (2002). Increasing student learning through multimedia projects. Virginia, Alexandria (USA): Association for Supervision and Curriculum Development.

Çiftçi, S., \& Sünbül, A. M. (2005). Creation and development of project-based learning approach. $1^{\text {st }}$ National Modern Approaches in Science and Technology Education Symposium, Ankara. Retrieved from http//:tef.selcuk.edu.tr/salan/sunbul/g/g16.doc

Curtis, D. (2002). Power of projects. The Journal of Educational Leadership, 60(1), 50-53.

Demirel, Ö. (1993). Educational terms dictionary. Ankara: Usem Publishing.

Demirel, Ö. (2007). Program development in education. Ankara: Pegem A Publishing.

Dori, Y., \& Tal, R. (2000) Formal and informal collaborate projects: Engaging in industry with environment awareness. Science Education, 84(1), 1-19.

Erdem, M. (2002). Project-based learning. Hacettepe University Faculty of Education Journal, 22(1), 172-179.

Erdem, M., \& Akkoyunlu, B. (2002). A study on project-based learning conducted with a team of $5^{\text {th }}$ grade students within the context of primary school social studies course. Elementary Education Online, 1(1), 2-11.

Gömleksiz, M. N., \& Fidan, E. K. (2013). A qualitative study on the use of project-based learning method in web design course. Mersin University Faculty of Education Journal, 9(1), 120-135.

Holzinger, A. (1997). Development of the problem solving behavior in physics education. A sectional and longitudinal study in Thermodynamics. Üniversity of Graz.

İçel, R. (2011). The impact of computer-aided instruction on mathematics achievements: The Geogebra Case. (Unpublished master's thesis), Selçuk University, Institute of Educational Sciences, Konya.

Kalayc1, N. (2008). An analysis of a project-based learning in higher education based on the students who managed the project. Education and Science, 33(147), 85-105.

Karasar, N. (2008). Scientific research methods. Ankara: Nobel Publishing.

Khaliq, S., Alam, M. T., \& Mushtaq, M. (2015). An experimental study to investigate the effectiveness of project-based learning (PBL) for teaching science at elementary level. International Journal of Academic Research in Progressive Education and Development, 4(1), 43-55. https://doi.org/10.6007/IJARPED/v4-i1/1434

Korkmaz, H., \& Kaptan, F. (2001). Project-based learning approach in science education. Hacettepe University Faculty of Education Journal, 20(20), 91-97. 
Nielsen, J. D., Du, X. Y., \& Kolmos, A. A. (2010). Innovative application of a new PBL model to interdisciplinary and intercultural projects. International Journal of Electrical Engineering Education, 47(2), 174-188.

Öztürk, B. (2012). The effect of Geogebra mathematics software on student achievements and Van Hiele geometry level in instruction of primary school $8^{\text {th }}$ grade mathematics course trigonometry and gradient. (Unpublished master's thesis), Sakarya University, Institute of Educational Sciences, Sakarya.

Özçakır, B., \& Çakıroğlu, E. (2017). Use of dynamic geometry software in the process of defining area correlations between quadrangles in junior high school $7^{\text {th }}$ grade. Ahi Evran University Kirşehir Faculty of Education Journal (KEFAD), 18(1), 231-248.

Özyurt, H., \& Özyurt, Ö. (2017). Analysis of student views on project-based learning experience in visual programming course. Turkish Journal of Computer and Mathematics Education, 8(2), 244-260. https://doi.org/10.16949/turkbilmat.285047

Saban, A. (2002). Learning teaching process. Ankara: Nobel Publishing \& Distribution.

Sert Çıbık, A. (2009). The impact of project-based learning approach on the attitudes of students towards the science course. Elementary Education Online, 8(1), 36-47.

Sharples, M. (2000). The design of personal mobile technologies for lifelong learning. Computers \& Education, 34(3), 177-193. https://doi.org/10.1016/S0360-1315(99)00044-5

Sharples, M., Corlett, D., \& Westmancott, O. (2002). The design and implementation of a mobile learning resource. Personal and Ubiquitous computing, 6(3), 220-234. https://doi.org/10.1007/s007790200021

Sidek, R. Z. S., \& Mohd Ariffin, S. (2011). Self-learning module AutoCAD computer-assisted design subjects 3D. UNSPECIFIED, 1(1), 1-9.

Thomas, J. W. (2000). A review of research on project based learning. Retrieved from http://www.k12reform.org/foundation/pbl/research

Vaiz, O. (2003). Use of portfolios (student development files) in project-based learning and its reflections on the learning process. (Unpublished master's thesis), Hacettepe University, Institute of Social Sciences, Ankara.

Yıldız, Z., \& Özdemir, A. Ş. (2012). The effect of the use of project-assisted instruction method on student achievements in the instruction of the topic of circle. M.U. Atatürk Faculty of Education Journal of Educational Sciences, 35, 175-187.

Zoller, U. (1991). Problem solving and the problem solving paradox in decision making-oriented environmental education. In S. Keiny \& U. Zoler (Eds.), Conceptual issues in environmental education publication (pp. 71-87). New York: Peter Lang Publication.

Winn, S. (1997). Learning by doing: Teaching research methods through student participation in a commissioned. Studies in Higher Education, 20(2), 203-214. https://doi.org/10.1080/03075079512331381703

\section{Appendix A}

\section{AutoCAD Achievement Test}

1. Which option below is used to save an active AutoCAD file with an alternative file name?
a) Save
b) Save as
c) New
d) Open

2. What is the function of Chamfer command?

a) Two lines are combined by rounding

b) It increases or reduces the object dimensions

c) To bevel the corners

d) To rotate the objects

3. Which command below is used to mark the desired object (line, arc, etc.) into equal parts using predetermined number of points or blocks?
a) Divide
b) Measure
c) Array
d) All

4. What is the shortcut for the "Area" command that measures the area? 

a) aa
b) ar
c) a
d) are

5. What is the shortcut used for cancelling a command?
a) Mouse right click
b) Space
c) Esc
d) $\mathrm{Tab}$

6. Which was is used to copy around a center point?
a) Copy
b) 3DArray
c) Array
d) Align

7. Files CANNOT be exported to which of the following formats using AutoCAD?
a). dwg
b). $\mathrm{dxf}$
c). jpeg
d). avi

8. Which is not available in Layer?
a) Render
b) Lock
c) Line weight
d) Line type

9. What is the function of Extend command?
a) Extension
b) Trimming
c) Deleting
d) Elevation

10. Which of the following does not accept the Trim command?
a) Line
b) Arc
c) Pline
d) Face

11. Which command is used to symmetrize an object?
a) Copy
b) Mirror
c) Move
d) Block

12. Which menu item includes editing commands?
a) View
b) Tools
c) Format
d) Modify

13. Which term reflects angle?
a) Scale
b) Rotate
c) Base
d) Angle

14. Scaling commands are located under which menu item in AUTOCAD?
a) Draw
b) Dimension
c) File
d) Modify

15. Pan command fulfills which purpose?
a) Zooms the image in and out.
b) Moves the drawn objects.
c) Slides the image.
d) Rotates the image in three dimensions.

16. What is the exact function of the Polar Array command?

a) Rotates the selected objects around a specified point and copies the objects.

b) Rotates the selected objects.

c) Copies the selected objects.

d) Alters the object dimensions.

17. Which should be used to draw a two-dimensional isometric drawing?
a) Ortho command.
b) End Point command is selected from Osnap > Settings.
c) Polar command.
d) Isometric snap mode is activated in Snap > Settings.

18. Which of the following is incorrect for the Ortho command?

a) Turned on and off with the F8 key.

b) Enables drawing parallel to the $\mathrm{x}$ and $\mathrm{y}$ axes of the drawing area. 
c) It is a transparent command (it can be turned on and off while in a command without exiting the command).

d) Turned on and off with the F3 key.

19. Which comment is used to print on paper using Plotter?
a) Print
b) Plot
c) Copy
d) Paste

20. Which is true for AutoCAD?

a) It is possible to add music to a drawing file with AUTOCAD.

b) AUTOCAD is a retouching and montage software for image files.

c) AUTOCAD is a vector drawing software.

d) AUTOCAD is used to edit movie files.

\section{Appendix B}

Applications Used in the Project-Based Learning Process

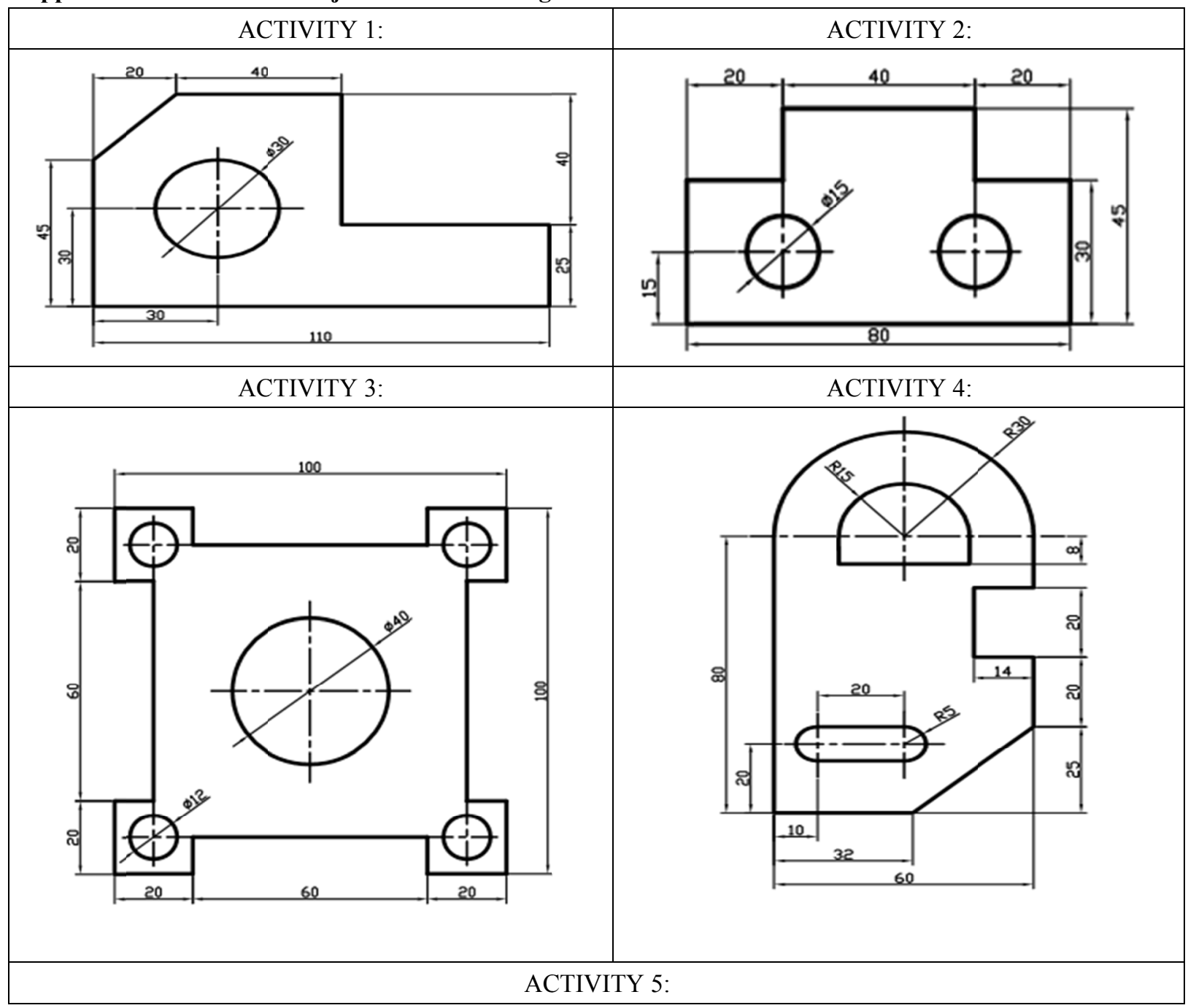




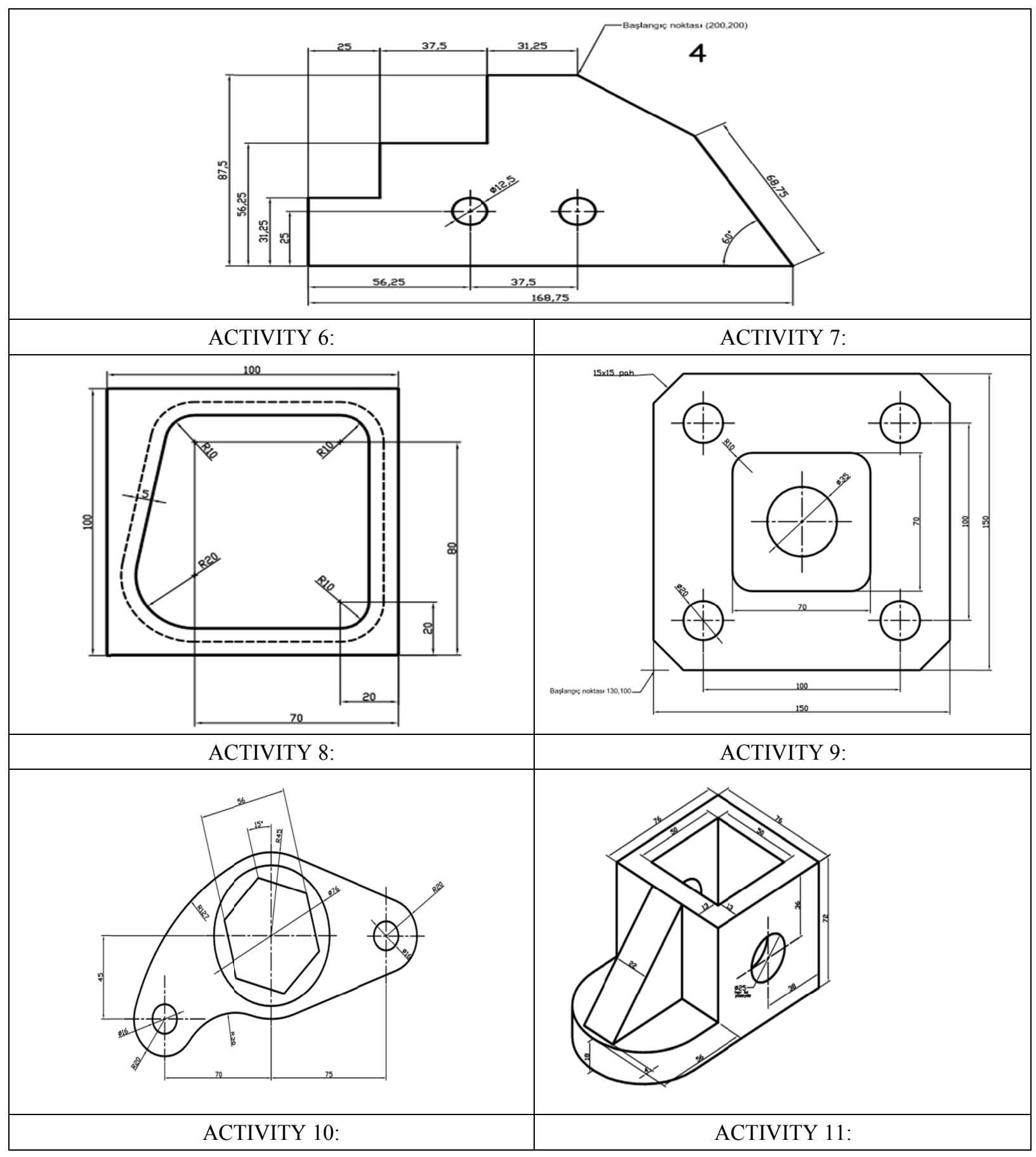




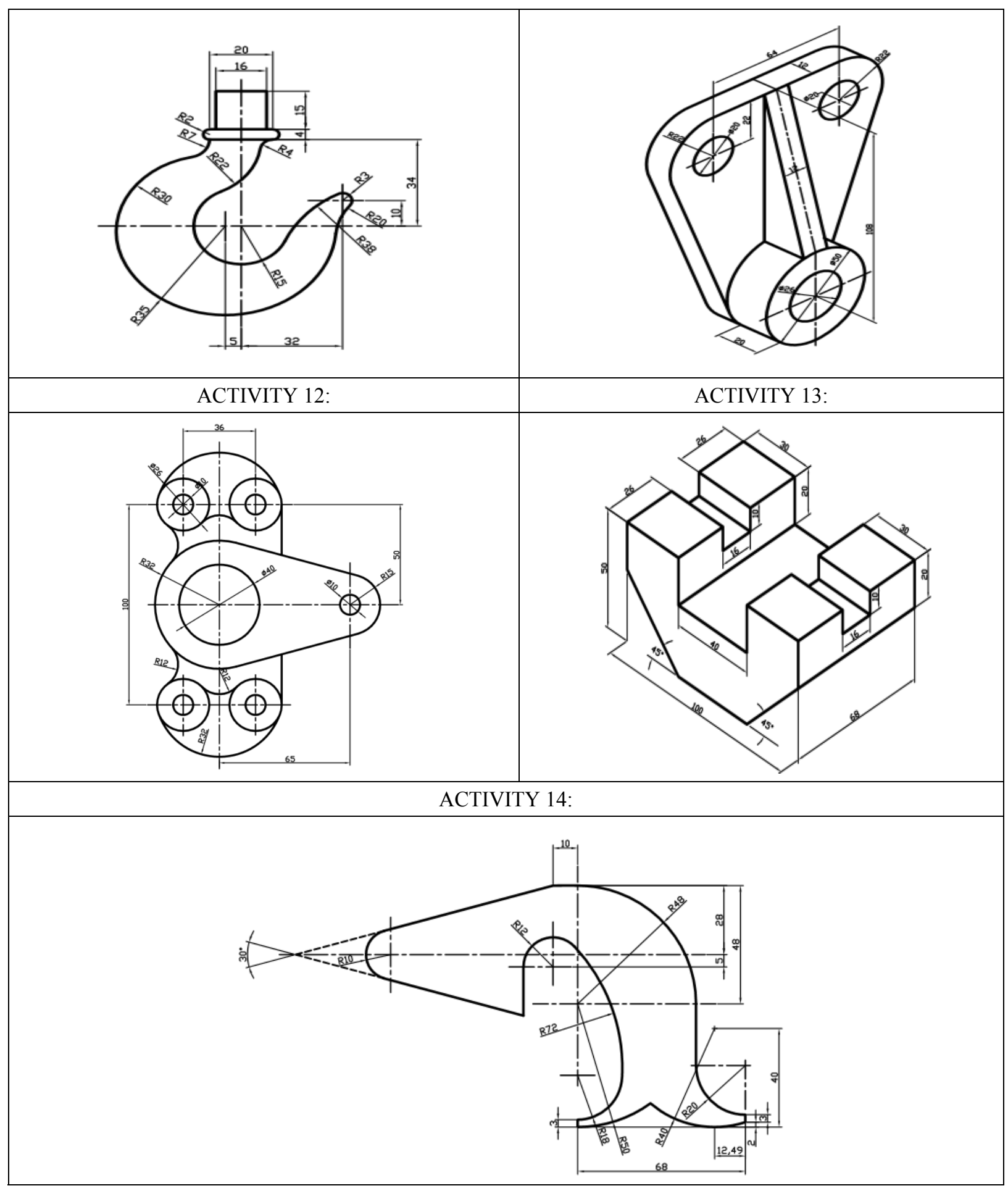

\section{Copyrights}

Copyright for this article is retained by the author, with first publication rights granted to the journal.

This is an open-access article distributed under the terms and conditions of the Creative Commons Attribution license (http://creativecommons.org/licenses/by/4.0/). 